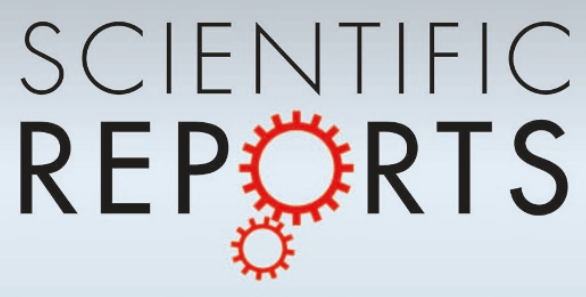

OPEN

SUBJECT AREAS:

ELECTRONIC MATERIALS

ELECTRONIC AND SPINTRONIC

DEVICES

Received

20 January 2014

Accepted

6 May 2014

Published

23 May 2014

Correspondence and requests for materials should be addressed to H.O. (hokamoto@cc. okayama-u.ac.jp) or R.E. (eguchi-r@cc. okayama-u.ac.jp)

\section{Transistor application of alkyl-substituted} picene

\author{
Hideki Okamoto', Shino Hamao², Hidenori Goto², Yusuke Sakai ${ }^{2}$, Masanari Izumi², Shin Gohda ${ }^{3}$, \\ Yoshihiro Kubozono ${ }^{2,4}$ \& Ritsuko Eguchi ${ }^{2}$
}

'Department of Chemistry, Okayama University, Okayama 700-8530, Japan, ${ }^{2}$ Research Laboratory for Surface Science, Okayama University, Okayama 700-8530, Japan, ${ }^{3}$ NARD Co. Ltd. Amagasaki, Amagasaki 660-0805, Japan, ${ }^{4}$ Research Center of New Functional Materials for Energy Production, Storage and Transport, Okayama University, Okayama 700-8530, Japan.

Field-effect transistors (FETs) were fabricated with a thin film of 3,10-ditetradecylpicene, picene- $\left(\mathrm{C}_{14} \mathrm{H}_{29}\right)_{2}$, formed using either a thermal deposition or a deposition from solution (solution process). All FETs showed p-channel normally-off characteristics. The field-effect mobility, $\mu$, in a picene- $\left(\mathrm{C}_{14} \mathrm{H}_{29}\right)_{2}$ thin-film FET with $\mathrm{PbZr}_{0.52} \mathrm{Ti}_{0.48} \mathrm{O}_{3}$ (PZT) gate dielectric reached $\sim 21 \mathrm{~cm}^{2} \mathrm{~V}^{-1} \mathrm{~s}^{-1}$, which is the highest $\mu$ value recorded for organic thin-film FETs; the average $\mu$ value $\left(\left\langle\mu>\right.\right.$ ) evaluated from twelve FET devices was $14(4) \mathrm{cm}^{2} \mathrm{~V}^{-1}$ $\mathrm{s}^{-1}$. The $\langle\mu\rangle$ values for picene- $\left(\mathrm{C}_{14} \mathrm{H}_{29}\right)_{2}$ thin-film FETs with other gate dielectrics such as $\mathrm{SiO}_{2}, \mathrm{Ta}_{2} \mathrm{O}_{5}$, $\mathrm{ZrO}_{2}$ and $\mathrm{HfO}_{2}$ were greater than $5 \mathrm{~cm}^{2} \mathrm{~V}^{-1} \mathrm{~s}^{-1}$, and the lowest absolute threshold voltage, $\left|V_{\mathrm{th}}\right|,(5.2 \mathrm{~V})$ was recorded with a PZT gate dielectric; the average $\left|V_{\text {th }}\right|$ for PZT gate dielectric is $7(1) \mathrm{V}$. The solution-processed picene- $\left(\mathrm{C}_{14} \mathrm{H}_{29}\right)_{2}$ FET was also fabricated with an $\mathrm{SiO}_{2}$ gate dielectric, yielding $\mu=3.4 \times$ $10^{-2} \mathrm{~cm}^{2} \mathrm{~V}^{-1} \mathrm{~s}^{-1}$. These results verify the effectiveness of picene- $\left(\mathrm{C}_{14} \mathrm{H}_{29}\right)_{2}$ for electronics applications.

igh-performance organic field-effect transistors (FETs) fabricated with various types of organic molecules have desirable characteristics such as light weight, mechanical flexibility, large area coverage, ease of design, and low-energy/low-cost fabrication ${ }^{1-28}$. The highest field-effect mobility, $\mu$, is presently $17.2 \mathrm{~cm}^{2} \mathrm{~V}^{-1} \mathrm{~s}^{-1}$ in thin-film organic FETs ${ }^{29}$ and $94 \mathrm{~cm}^{2} \mathrm{~V}^{-1} \mathrm{~s}^{-1}$ in single-crystal organic FETs ${ }^{22}$. In particular, the promise of [n]phenacene-type molecules ([5]phenacene (picene), [6]phenacene, and [7]phenacene) in transistors is being discussed based on the excellent FET characteristics already observed ${ }^{13-17}$. The [n]phenacene molecule has an armchair-shaped molecular structure, and its large band gap and deep valence band suggest that these molecules are chemically stable even in atmospheric conditions ${ }^{13,28}$. Such characteristics are very desirable for transistor applications, as transistors must be durable under repeated use over the long term. However, one of the problems presented by pentacene itself in transistor applications is chemical instability under atmospheric conditions, although pentacene is the organic molecule most commonly used for transistors ${ }^{3-12}$. Therefore, [n]phenacene molecules may be superior to pentacene and its analogues (acene molecules) in transistor applications.

Here, we report the fabrication of an FET device with a new alkyl-substituted picene, and its FET characteristics. A 3,10-ditetradecylpicene (picene- $\left.\left(\mathrm{C}_{14} \mathrm{H}_{29}\right)_{2}\right)$ thin-film FET shows excellent characteristics, with its highest $\mu$ value reaching $21 \mathrm{~cm}^{2} \mathrm{~V}^{-1} \mathrm{~s}^{-1}$ with a $\mathrm{PbZr}_{0.52} \mathrm{Ti}_{0.48} \mathrm{O}_{3}(\mathrm{PZT})$ gate dielectric. This may be the highest value reported in an organic thin-film FET to date ${ }^{29,30}$. The solution-deposited-film FET device was fabricated with $\mathrm{CHCl}_{3}$ solvent. Topological characterization of thin films of picene- $\left(\mathrm{C}_{14} \mathrm{H}_{29}\right)_{2}$ was performed using X-ray diffraction (XRD) and atomic force microscopy (AFM). The structure of the picene- $\left(\mathrm{C}_{14} \mathrm{H}_{29}\right)_{2}$ molecule and the device structure are shown in Figures 1(a) and (b), respectively.

\section{Results}

Morphology of picene- $\left(\mathrm{C}_{\mathbf{1 4}} \mathbf{H}_{29}\right)_{2}$ thin film. The XRD pattern of a picene- $\left(\mathrm{C}_{14} \mathrm{H}_{29}\right)_{2}$ thin film formed on an $\mathrm{SiO}_{2}$ surface is shown in Figure 1(c), and only a small 001 and a pronounced 100 reflections are observed, implying the absence of parallel planes stacked on the surface. Therefore, this stacking pattern is different from that of thin films of other phenacene molecules, in which the $a b$-plane is parallel-stacked on the $\mathrm{SiO}_{2}$ surface, because there only $00 l$ reflections are observed ${ }^{16,18,20,31}$. The $d_{100}$ which refers to the $b c$-layer spacing can be determined to be $1.368 \mathrm{~nm}$, where the space group is assumed to be the same as that of picene (monoclinic: No. 4, P2 $2_{1}$ ). The $d_{001}$ which refers to the $a b$-plane spacing was $4.052 \mathrm{~nm}$, which is comparable to the long axis of picene- $\left(\mathrm{C}_{14} \mathrm{H}_{29}\right)_{2}$, $4.9 \mathrm{~nm}$. Since this distance is too long, the structure may be different from other phenacenes. The inclination angle of picene- $\left(\mathrm{C}_{14} \mathrm{H}_{29}\right)_{2}$ with respect to the reciprocal lattice $c^{*}\left(\left|c^{*}\right|=1 / d_{001}\right)$ is estimated to be $\sim 30^{\circ}$ which is 
a

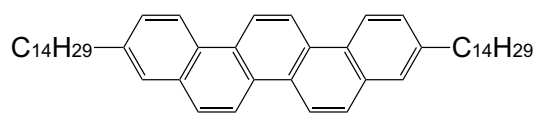

b

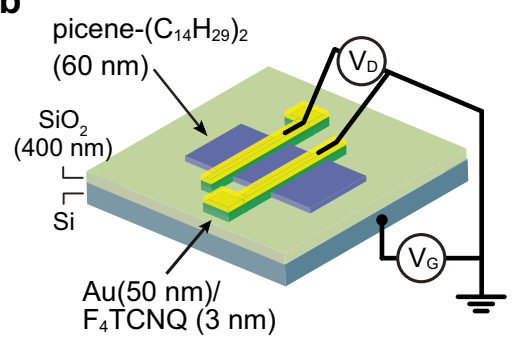

d
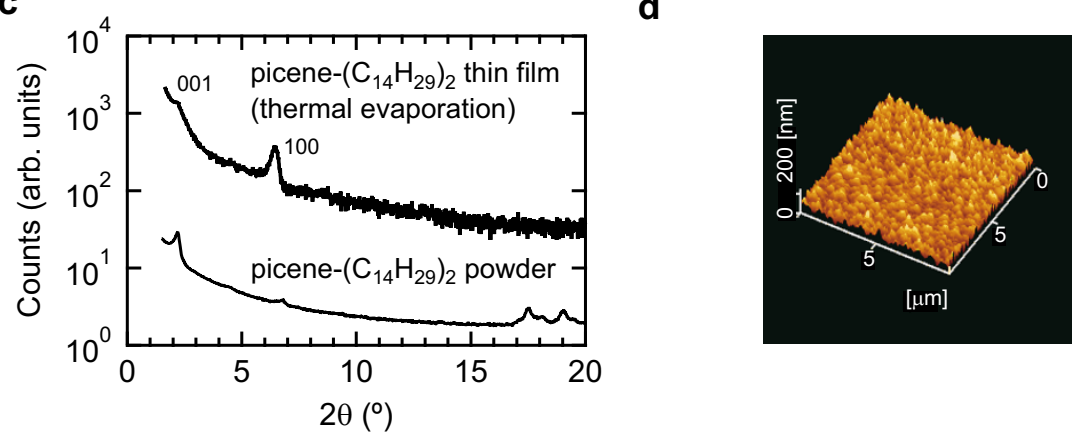

Figure $1 \mid$ (a) Molecular structure of picene- $\left(\mathrm{C}_{14} \mathrm{H}_{29}\right)_{2}$. (b) Structure of picene- $\left(\mathrm{C}_{14} \mathrm{H}_{29}\right)_{2}$ thin-film FET. (c) XRD pattern of picene- $\left(\mathrm{C}_{14} \mathrm{H}_{29}\right)_{2}$ thin film and powder. (d) AFM image of picene- $\left(\mathrm{C}_{14} \mathrm{H}_{29}\right)_{2}$ thin film.

almost the same as that of other phenacenes ${ }^{16,18,20,31}$. The XRD pattern of a powder sample of picene- $\left(\mathrm{C}_{14} \mathrm{H}_{29}\right)_{2}$ is shown in Figures $1(\mathrm{c})$ and $3(\mathrm{~b})$. The $a, b, c$ and $\beta$ were determined to be $1.3192(8), 0.5516(2)$, $4.0953(5) \mathrm{nm}$ and $92.67(2)^{\circ}$, respectively, using LeBail fitting. The $a$ and $c$ of the powder are the same as those of a thin film, $1.370 \mathrm{~nm}$ and $4.057 \mathrm{~nm}$, respectively, where the $\beta$ in a thin film is assumed to be the same as that of powder. The crystallite size of thin film is evaluated to be $25 \mathrm{~nm}$, from 100 reflections and the Debye-Scherrer formula; the grain size refers to the 100 direction.

An AFM image of a picene- $\left(\mathrm{C}_{14} \mathrm{H}_{29}\right)_{2}$ thin film (60 nm thick) formed by thermal deposition on an $\mathrm{SiO}_{2}$ surface is shown in Figure 1(d). The AFM image shows the presence of grains of 100$1000 \mathrm{~nm}$. The average grain size in the thin film (Figure 1(d)) is $600 \mathrm{~nm}$ and the root-mean-square (rms) surface roughness is $28 \mathrm{~nm}$. The average grain size is larger than the $540 \mathrm{~nm}$ of picene thin film, while the rms surface roughness is much larger than picene's $3.1 \mathrm{~nm}^{16}$. This may be due to the long axis of the molecule or the presence of long alkyl chains. Judging from the difference between grain size $(\sim 600 \mathrm{~nm})$ from the AFM image and crystallite size $(\sim 25 \mathrm{~nm})$ from $\mathrm{X}$-ray diffraction, a grain recognized by AFM consists of $\sim 10^{4}$ crystallites.

FET characteristics of thin-film FET with a picene- $\left(\mathrm{C}_{14} \mathrm{H}_{29}\right)_{2}$ formed by thermal deposition. The output and transfer curves of a picene- $\left(\mathrm{C}_{14} \mathrm{H}_{29}\right)_{2}$ thin-film $\mathrm{FET}$ with an $\mathrm{SiO}_{2}$ gate dielectric are shown in Figures 2(a) and (b). Typical p-channel FET characteristics are observed in both graphs. The output curves show clear linear and saturation behaviour in low and high absolute drainvoltage, $\left|V_{\mathrm{D}}\right|$, regimes, respectively; the drain-voltage, $V_{\mathrm{D}}$, and gate-voltage, $V_{\mathrm{G}}$, applied are negative, since this device operates in p-channel. From this transfer curve at $V_{\mathrm{D}}=-80 \mathrm{~V}$ (saturation regime), the $\mu$, threshold voltage $V_{\mathrm{th}}$, on-off ratio and subthreshold swing $S$ are determined to be $3.9 \mathrm{~cm}^{2} \mathrm{~V}^{-1} \mathrm{~s}^{-1},-51 \mathrm{~V}$, $2.2 \times 10^{6}$ and $6.6 \mathrm{~V}$ decade ${ }^{-1}$, respectively.

The average $\mu$ value $(\langle\mu\rangle)$, average $V_{\text {th }}\left(\left\langle V_{\text {th }}\right\rangle\right)$, average on-off ratio (<on-off ratio $>$ ), and average $S(<S>$ ) from seven picene$\left(\mathrm{C}_{14} \mathrm{H}_{29}\right)_{2}$ FETs with $\mathrm{SiO}_{2}$ gate dielectric are $7(2) \mathrm{cm}^{2} \mathrm{~V}^{-1} \mathrm{~s}^{-1}$, $-30(10) \mathrm{V}, 6(4) \times 10^{6}$, and $3(2) \mathrm{V}$ decade $^{-1}$, respectively. The highest $\mu$ value reaches $9.5 \mathrm{~cm}^{2} \mathrm{~V}^{-1} \mathrm{~s}^{-1}$. Thus, the picene- $\left(\mathrm{C}_{14} \mathrm{H}_{29}\right)_{2}$ FET shows excellent FET characteristics. All FET parameters in seven FETs are shown in Table 1.

Here we briefly comment on the presence of hysteresis (or difference between forward and reverse curves) in transfer and output curves of picene- $\left(\mathrm{C}_{14} \mathrm{H}_{29}\right)_{2}$ FETs. The hysteresis in picene thin-film FET is previously investigated, which concludes that the hysteresis is closely related to enhancement of trap states $\left(\mathrm{H}_{2} \mathrm{O}\right.$-related trap states) caused by electric field under the presence of $\mathrm{H}_{2} \mathrm{O}$ at the interface between organic thin-film and gate dielectric ${ }^{15,17}$, i.e., the mechanism is called as bias-stress effect. Therefore, the hysteresis observed in the picene- $\left(\mathrm{C}_{14} \mathrm{H}_{29}\right)_{2}$ FETs may also be produced by bias-stress effect due to $\mathrm{H}_{2} \mathrm{O}$ and strong electric-field.

The FET properties were measured after keeping the devices under atmospheric condition or high temperature in order to clarify the durability. The $\mu$ values of three picene- $\left(\mathrm{C}_{14} \mathrm{H}_{29}\right)_{2}$ FETs with $\mathrm{SiO}_{2}$ gate dielectric are evaluated in each experiment. The variation of $\mu$ after keeping the FET in atmosphere is shown as a function of time in Figure S9(a). The $\mu$ values do not change even if the FETs are stored in atmosphere for 7 days. On the other hand, as seen from Figure S9(b), the $\mu$ values drastically decrease when heating the FETs above $100^{\circ} \mathrm{C}$ for $1 \mathrm{~h}$, implying that the picene- $\left(\mathrm{C}_{14} \mathrm{H}_{29}\right)_{2}$ thin-film deteriorates at high temperature, i.e., picene- $\left(\mathrm{C}_{14} \mathrm{H}_{29}\right)_{2}$ molecule probably sublimes. As a consequence, the picene- $\left(\mathrm{C}_{14} \mathrm{H}_{29}\right)_{2}$ FET is stable under atmospheric condition, while it deteriorates above $100^{\circ} \mathrm{C}$.

The transfer curves of picene- $\left(\mathrm{C}_{14} \mathrm{H}_{29}\right)_{2}$ thin-film FETs with $\mathrm{HfO}_{2}$ and PZT are shown in Figures 2(c) and (d), respectively; these also show p-channel FET characteristics. The $\mu, V_{\text {th }}$, on-off ratio and $S$ were $7.7 \mathrm{~cm}^{2} \mathrm{~V}^{-1} \mathrm{~s}^{-1},-11 \mathrm{~V}, 3.4 \times 10^{6}$ and $1.1 \mathrm{~V}$ decade ${ }^{-1}$, respectively, for a picene- $\left(\mathrm{C}_{14} \mathrm{H}_{29}\right)_{2}$ thin-film $\mathrm{FET}$ with an $\mathrm{HfO}_{2}$ gate dielectric, becoming $13 \mathrm{~cm}^{2} \mathrm{~V}^{-1} \mathrm{~s}^{-1},-9.8 \mathrm{~V}, 1.6 \times 10^{6}$ and $9.8 \times 10^{-1} \mathrm{~V}$ decade ${ }^{-1}$, respectively, for a picene- $\left(\mathrm{C}_{14} \mathrm{H}_{29}\right)_{2}$ thin-film FET with a PZT gate dielectric. We made additional picene- $\left(\mathrm{C}_{14} \mathrm{H}_{29}\right)_{2}$ thin-film FETs with $\mathrm{ZrO}_{2}$ and $\mathrm{Ta}_{2} \mathrm{O}_{5}$ gate dielectrics (Figure $\mathrm{S} 6$ in Supplementary information). The $\mu$ values are $7.0 \mathrm{~cm}^{2} \mathrm{~V}^{-1} \mathrm{~s}^{-1}$ for $\mathrm{ZrO}_{2}$ and $6.3 \mathrm{~cm}^{2} \mathrm{~V}^{-1} \mathrm{~s}^{-1}$ for $\mathrm{Ta}_{2} \mathrm{O}_{5}$. The $\langle\mu\rangle,\left\langle V_{\mathrm{th}}\right\rangle$, $<$ on-off ratio $>$, and $\langle S\rangle$ from five picene- $\left(\mathrm{C}_{14} \mathrm{H}_{29}\right)_{2}$ FETs with $\mathrm{HfO}_{2}$ gate dielectric are 5(1) $\mathrm{cm}^{2} \mathrm{~V}^{-1} \mathrm{~s}^{-1},-10.4(5) \mathrm{V}, 8(15) \times 10^{5}$, and 


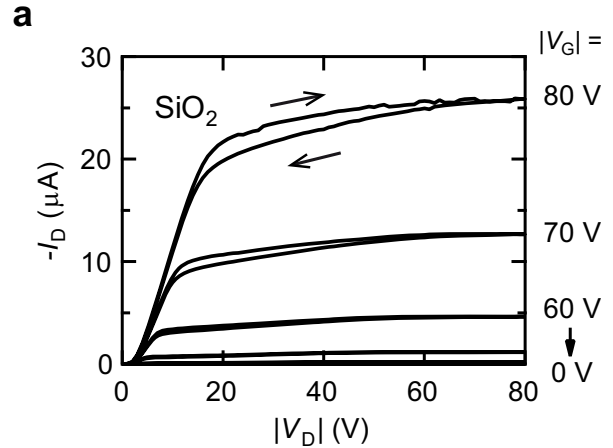

C

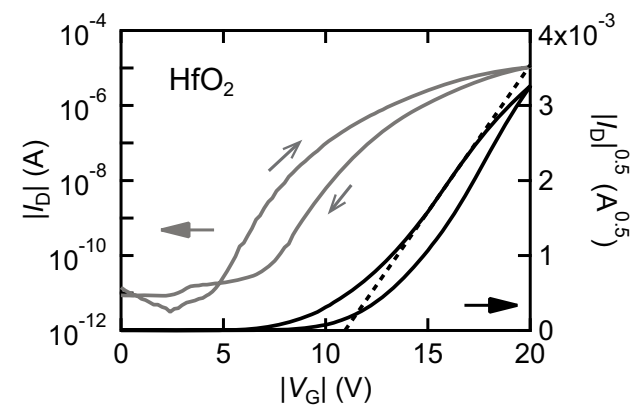

b

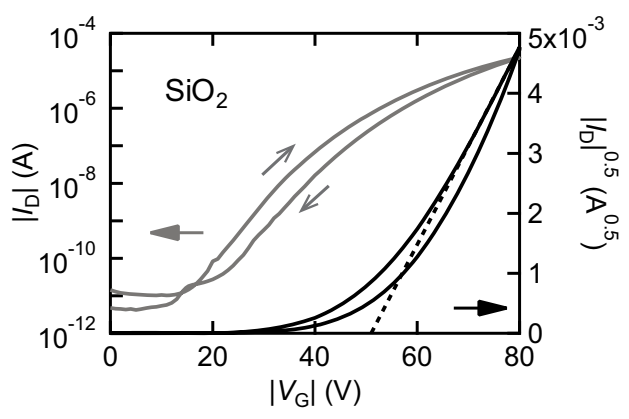

d

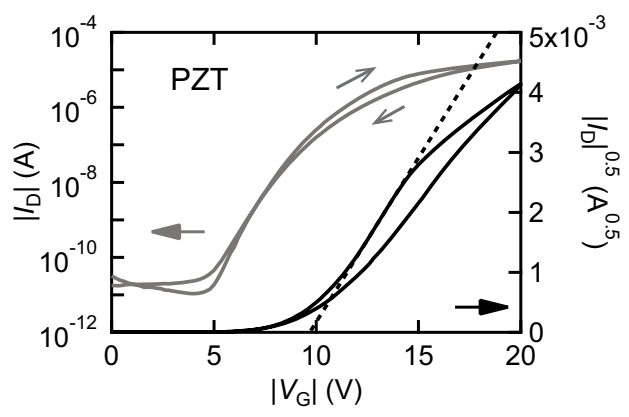

Figure $2 \mid$ (a) Output and (b) transfer curves of a picene- $\left(\mathrm{C}_{14} \mathrm{H}_{29}\right)_{2}$ thin-film FET with $\mathrm{SiO}_{2}$ gate dielectric. Transfer curves of a picene- $\left(\mathrm{C}_{14} \mathrm{H}_{29}\right)_{2}$ thinfilm FET with (c) $\mathrm{HfO}_{2}$ and (d) PZT. In (b), $V_{\mathrm{D}}=-80 \mathrm{~V}$; in (c) and (d), $V_{\mathrm{D}}=-20 \mathrm{~V}$. The FETs used for measurements correspond to the sample \#1 in each table (Table 1, 2 and 3). $L$ and $W$ were 300 and $500 \mu \mathrm{m}$ for $\mathrm{SiO}_{2}$, respectively, 450 and $500 \mu \mathrm{m}$ for $\mathrm{HfO}_{2}$, and 450 and $600 \mu \mathrm{m}$ for PZT.

1.4(2) $\mathrm{V}$ decade ${ }^{-1}$, respectively, while the $\langle\mu\rangle,\left\langle V_{\text {th }}\right\rangle$, $<$ on-off ratio $>$, and $\left\langle S>\right.$ from twelve picene- $\left(\mathrm{C}_{14} \mathrm{H}_{29}\right)_{2}$ FETs with $\mathrm{PZT}$ gate dielectric are 14(4) $\mathrm{cm}^{2} \mathrm{~V}^{-1} \mathrm{~s}^{-1},-7(1) \mathrm{V}, 2.4(7) \times 10^{6}$, and $0.9(1) \mathrm{V}$ decade $^{-1}$. The highest $\mu$ value reaches $20.9 \mathrm{~cm}^{2} \mathrm{~V}^{-1} \mathrm{~s}^{-1}$ in picene$\left(\mathrm{C}_{14} \mathrm{H}_{29}\right)_{2}$ FET with PZT gate dielectric. All FET parameters in FETs with $\mathrm{HfO}_{2}$ and PZT are shown in Table 2 and 3, respectively. Thus, the $\mu$ values are quite high in picene- $\left(\mathrm{C}_{14} \mathrm{H}_{29}\right)_{2}$ thin-film FETs with high $k$-dielectrics. In particular, the picene- $\left(\mathrm{C}_{14} \mathrm{H}_{29}\right)_{2}$ FET with PZT gate dielectric accompanies both high mobility and low-voltage operation. To our knowledge, the $\mu$ value, $20.9 \mathrm{~cm}^{2} \mathrm{~V}^{-1} \mathrm{~s}^{-1}$, recorded in this study is the highest in organic thin-film FETs at the present stage. The FET parameters recorded for picene- $\left(\mathrm{C}_{14} \mathrm{H}_{29}\right)_{2}$ FET with $\mathrm{Ta}_{2} \mathrm{O}_{5}$ (six FETs) and $\mathrm{ZrO}_{2}$ (six FETs) gate dielectrics are shown in Table 4 and 5, respectively, together with their average values.

The output curves of picene- $\left(\mathrm{C}_{14} \mathrm{H}_{29}\right)_{2}$ FETs with high $k$-gate dielectrics (Figure S7 in Supplementary information) show p-channel FET characteristics with clear saturation behaviour in the high $\left|V_{\mathrm{D}}\right|$ regime, but a little concave behaviour in the low $\left|V_{\mathrm{D}}\right|$ regime, which indicates a large contact resistance, in spite of the presence of a $3 \mathrm{~nm}$ thick 2,3,5,6-tetrafluoro-7,7,8,8-tetracyanoquinodimethane $\left(\mathrm{F}_{4} \mathrm{TCNQ}\right)$ layer between the source/drain electrodes and the

Table 1 | FET characteristics of picene- $\left(\mathrm{C}_{14} \mathrm{H}_{29}\right)_{2}$ thin film FETs with an $\mathrm{SiO}_{2}$ dielectric. $\mathrm{W}=500 \mu \mathrm{m}$

\begin{tabular}{lccccc} 
sample & $\mu\left(\mathrm{cm}^{2} \mathrm{~V}^{-1} \mathrm{~s}^{-1}\right)$ & $\left|V_{\mathrm{th}}\right|(\mathrm{V})$ & ON/OFF & $S(\mathrm{~V} /$ decade $)$ & $L(\mu \mathrm{m})$ \\
\hline$\# 1$ & 3.9 & 51.0 & $2.2 \times 10^{6}$ & 6.6 & 300 \\
$\# 2$ & 8.0 & 26.1 & $1.5 \times 10^{7}$ & 2.7 & 200 \\
$\# 3$ & 7.8 & 37.6 & $3.4 \times 10^{6}$ & 3.6 & 250 \\
$\# 4$ & 9.5 & 35.0 & $6.8 \times 10^{6}$ & 2.9 & 300 \\
$\# 5$ & 7.0 & 28.3 & $4.6 \times 10^{6}$ & 2.8 & 350 \\
$\# 6$ & 6.6 & 18.8 & $8.2 \times 10^{6}$ & 1.9 & 450 \\
$\# 7$ & 7.0 & 21.5 & $5.1 \times 10^{6}$ & 2.6 & 450 \\
average & $7(2)$ & $30(10)$ & $6(4) \times 10^{6}$ & $3(2)$ & \\
\hline
\end{tabular}

picene- $\left(\mathrm{C}_{14} \mathrm{H}_{29}\right)_{2}$ thin film. The origin of this resistance is still not clear, and a design to lower it is necessary for picene- $\left(\mathrm{C}_{14} \mathrm{H}_{29}\right)_{2}$ thinfilm FETs with high- $k$ gate dielectrics.

FET characteristics of solution-processed picene- $\left(\mathrm{C}_{14} \mathrm{H}_{29}\right)_{2}$ thinfilm FET. Finally, we fabricated a picene- $\left(\mathrm{C}_{14} \mathrm{H}_{29}\right)_{2}$ thin-film FET by depositing the film from solution, and measured its FET characteristics. An optical image of the thin film is shown in Figure 3(a), showing large grains. The XRD pattern of the thin film is shown in Figure 3(b) together with that of a powder sample, which differs from that of the thin film formed by thermal deposition (Figure 1(c)) and is similar to that of powder. This pattern implies that there is no parallel stacking of layers on $\mathrm{SiO}_{2}$ surface. Actually, as indicated from the optical image, the grains aggregate on the $\mathrm{SiO}_{2}$ surface, indicating a strong interaction between grains, as small granules precipitate from the solution.

The output and transfer curves of a solution-deposited picene$\left(\mathrm{C}_{14} \mathrm{H}_{29}\right)_{2}$ thin-film FET are shown in Figures 3(c) and (d), respectively. These show p-channel FET characteristics, and the $\mu, V_{\mathrm{th}}$, on-off ratio and $S$ are $3.4 \times 10^{-2} \mathrm{~cm}^{2} \mathrm{~V}^{-1} \mathrm{~s}^{-1},-48 \mathrm{~V}, 3.3 \times 10^{5}$ and $6.1 \mathrm{~V} \mathrm{decade}^{-1}$, respectively. The $\mu$ value of a solution-deposited picene- $\left(\mathrm{C}_{14} \mathrm{H}_{29}\right)_{2}$ thin-film FET observed in this study is lower by

Table 2 | FET characteristics of picene- $\left(\mathrm{C}_{14} \mathrm{H}_{29}\right)_{2}$ thin film FETs with an $\mathrm{HfO}_{2}$ dielectric. $W=500 \mu \mathrm{m}$

\begin{tabular}{lccccc} 
sample & $\mu\left(\mathrm{cm}^{2} \mathrm{~V}^{-1} \mathrm{~s}^{-1}\right)$ & $\left|V_{\text {th }}\right|(\mathrm{V})$ & ON/OFF & $S(\mathrm{~V} /$ decade $)$ & $L(\mu \mathrm{m})$ \\
\hline$\# 1$ & 7.7 & 10.92 & $3.4 \times 10^{6}$ & 1.08 & 450 \\
$\# 2$ & 4.2 & 10.61 & $1.2 \times 10^{5}$ & 1.16 & 350 \\
$\# 3$ & 4.6 & 10.00 & $1.1 \times 10^{5}$ & 1.40 & 450 \\
$\# 4$ & 4.8 & 9.78 & $1.4 \times 10^{5}$ & 1.50 & 450 \\
$\# 5$ & 5.6 & 10.84 & $5.1 \times 10^{3}$ & 1.68 & 600 \\
average & $5(1)$ & $10.4(5)$ & $8(15) \times 10^{5}$ & $1.4(2)$ & \\
\hline
\end{tabular}




\begin{tabular}{|lccccc|}
\hline \multicolumn{5}{|l|}{ Table 3 } & FET characteristics of picene- $\left(\mathrm{C}_{14} \mathrm{H}_{29}\right)_{2}$ thin film FETs with \\
a PZT dielectric. $W=600 \mu \mathrm{m}$ & & \\
sample & $\mu\left(\mathrm{cm}^{2} \mathrm{~V}^{-1} \mathrm{~s}^{-1}\right)$ & $\left|V_{\text {th }}\right|(\mathrm{V})$ & ON/OFF & $S(\mathrm{~V} /$ decade $)$ & $L(\mu \mathrm{m})$ \\
\hline$\# 1$ & 13.1 & 9.8 & $1.6 \times 10^{6}$ & 0.98 & 450 \\
$\# 2$ & 10.3 & 6.5 & $3.0 \times 10^{6}$ & 0.74 & 150 \\
$\# 3$ & 12.9 & 6.7 & $3.6 \times 10^{6}$ & 0.75 & 150 \\
$\# 4$ & 14.3 & 6.6 & $2.9 \times 10^{6}$ & 0.65 & 200 \\
$\# 5$ & 13.0 & 6.6 & $2.5 \times 10^{6}$ & 0.71 & 200 \\
$\# 6$ & 9.3 & 5.6 & $3.1 \times 10^{6}$ & 0.89 & 200 \\
$\# 7$ & 13.0 & 6.6 & $2.5 \times 10^{6}$ & 0.90 & 200 \\
$\# 8$ & 20.9 & 7.9 & $2.3 \times 10^{6}$ & 0.81 & 300 \\
$\# 9$ & 17.9 & 6.5 & $2.0 \times 10^{6}$ & 0.84 & 300 \\
$\# 10$ & 11.4 & 5.8 & $1.9 \times 10^{6}$ & 1.1 & 300 \\
$\# 11$ & 15.8 & 6.8 & $2.2 \times 10^{6}$ & 1.1 & 300 \\
$\# 12$ & 19.7 & 5.2 & $8.9 \times 10^{5}$ & 1.0 & 450 \\
average & $14(4)$ & $7(1)$ & $2.4(7) \times 10^{6}$ & $0.9(1)$ & \\
\hline
\end{tabular}

two orders of magnitude than that, $2.0 \mathrm{~cm}^{2} \mathrm{~V}^{-1} \mathrm{~s}^{-1}$, previously reported $^{32}$.

\section{Discussion}

We have succeeded in fabricating a high-performance picene$\left(\mathrm{C}_{14} \mathrm{H}_{29}\right)_{2}$ thin-film FET with various gate dielectrics. Here, the characteristics observed are discussed and the strategy for a further improvement will be presented.

The $\langle\mu\rangle$ value, $7(2) \mathrm{cm}^{2} \mathrm{~V}^{-1} \mathrm{~s}^{-1}$, in a picene- $\left(\mathrm{C}_{14} \mathrm{H}_{29}\right)_{2}$ thin film FET with $\mathrm{SiO}_{2}$ gate dielectric was higher than those of thin-film FETs with picene $\left(1.0-3.0 \mathrm{~cm}^{2} \mathrm{~V}^{-1} \mathrm{~s}^{-1}\right)^{13,14}$ and [7]phenacene $\left(0.8 \mathrm{~cm}^{2} \mathrm{~V}^{-1} \mathrm{~s}^{-1}\right)^{20}$, while comparable to that $\left(7.4 \mathrm{~cm}^{2} \mathrm{~V}^{-1} \mathrm{~s}^{-1}\right)^{19}$ of a [6]phenacene thin-film FET. Despite the absence of parallel planes stacked on the $\mathrm{SiO}_{2}$ surface, the $\langle\mu\rangle$ value is higher than that of thin-film FET with picene, suggesting a presence of other factor such as high overlap (transfer integral) between molecules in picene- $\left(\mathrm{C}_{14} \mathrm{H}_{29}\right)_{2}$ thin film. Here it is important to notice that a $3 \mathrm{~nm}$ layer of $\mathrm{F}_{4} \mathrm{TCNQ}$ is inserted between the electrodes and the thin film. This should provide a small Schottky barrier height (or a small contact resistance) and a low $\left|V_{\mathrm{th}}\right|$ as reported previously for organic single-crystal FETs ${ }^{27}$.

The $\langle\mu\rangle$ values in picene- $\left(\mathrm{C}_{14} \mathrm{H}_{29}\right)_{2}$ thin film FETs with high- $k$ gate dielectrics $\left(5(1) \mathrm{cm}^{2} \mathrm{~V}^{-1} \mathrm{~s}^{-1}\right.$ for $\mathrm{HfO}_{2}, 14(4) \mathrm{cm}^{2} \mathrm{~V}^{-1} \mathrm{~s}^{-1}$ for PZT, 5(2) $\mathrm{cm}^{2} \mathrm{~V}^{-1} \mathrm{~s}^{-1}$ for $\mathrm{Ta}_{2} \mathrm{O}_{5}$ and $9(2) \mathrm{cm}^{2} \mathrm{~V}^{-1} \mathrm{~s}^{-1}$ for $\mathrm{ZrO}_{2}$ ) are comparable to that, $7(2) \mathrm{cm}^{2} \mathrm{~V}^{-1} \mathrm{~s}^{-1}$, for a picene- $\left(\mathrm{C}_{14} \mathrm{H}_{29}\right)_{2}$ thinfilm FET with an $\mathrm{SiO}_{2}$ gate dielectric, as seen from Tables 1-5. It is worth noting that the maximum $\mu$ value, $20.9 \mathrm{~cm}^{2} \mathrm{~V}^{-1} \mathrm{~s}^{-1}$, for picene- $\left(\mathrm{C}_{14} \mathrm{H}_{29}\right)_{2}$ thin-film FET with PZT gate dielectric (Table 3) is the highest value yet reported for organic FETs; as seen from Table 5, the $\mu$ value as high as $23.3 \mathrm{~cm}^{2} \mathrm{~V}^{-1} \mathrm{~s}^{-1}$ is observed, but the value is not included in discussion because it is much higher than the other $\mu$ values listed in Table 5. Currently, the highest $\mu$ is $17.2 \mathrm{~cm}^{2} \quad \mathrm{~V}^{-1} \mathrm{~s}^{-1}$ for a bis(benzothieno)naphthalene thin-film

Table $4 \mid$ FET characteristics of picene- $\left(\mathrm{C}_{14} \mathrm{H}_{29}\right)_{2}$ thin film FETs with $\mathrm{a} \mathrm{Ta}_{2} \mathrm{O}_{5}$ dielectric. $\mathrm{W}=500 \mu \mathrm{m}$ except for sample $\# 1$, and $W=$ $600 \mu \mathrm{m}$ for sample \# 1

\begin{tabular}{lccccc} 
sample & $\mu\left(\mathrm{cm}^{2} \mathrm{~V}^{-1} \mathrm{~s}^{-1}\right)$ & $\left|V_{\text {th }}\right|(\mathrm{V})$ & ON/OFF & $S(\mathrm{~V} /$ decade $)$ & $L(\mu \mathrm{m})$ \\
\hline$\# 1$ & 6.3 & 13.0 & $4.6 \times 10^{6}$ & 1.13 & 450 \\
$\# 2$ & 3.3 & 10.9 & $1.6 \times 10^{5}$ & 0.710 & 300 \\
$\# 3$ & 4.9 & 9.33 & $2.4 \times 10^{5}$ & 1.19 & 450 \\
$\# 4$ & 6.4 & 9.91 & $2.7 \times 10^{5}$ & 1.15 & 450 \\
$\# 5$ & 7.6 & 10.5 & $2.5 \times 10^{5}$ & 1.13 & 450 \\
$\# 6$ & 4.6 & 10.0 & $1.6 \times 10^{5}$ & 1.04 & 600 \\
average & $5(2)$ & $11(1)$ & $9(18) \times 10^{5}$ & $1.0(2)$ & \\
\hline
\end{tabular}

Table 5 | FET characteristics of picene- $\left(\mathrm{C}_{14} \mathrm{H}_{29}\right)_{2}$ thin film FETs with a $\mathrm{ZrO}_{2}$ dielectric. $\mathrm{W}=500 \mu \mathrm{m}$

\begin{tabular}{lccccc} 
sample & $\mu\left(\mathrm{cm}^{2} \mathrm{~V}^{-1} \mathrm{~s}^{-1}\right)$ & $\left|V_{\text {th }}\right|(\mathrm{V})$ & ON/OFF & $S(\mathrm{~V} /$ decade $)$ & $L(\mu \mathrm{m})$ \\
\hline$\# 1$ & 7.0 & 10.8 & $1.1 \times 10^{7}$ & 0.43 & 450 \\
$\# 2$ & 8.9 & 7.6 & $1.4 \times 10^{6}$ & 0.40 & 135 \\
$\# 3$ & 9.6 & 7.4 & $1.0 \times 10^{6}$ & 0.84 & 200 \\
$\# 4$ & 8.6 & 6.1 & $7.0 \times 10^{5}$ & 0.89 & 300 \\
$\# 5$ & 12.0 & 8.2 & $4.1 \times 10^{5}$ & 0.86 & 450 \\
$\# 6$ & 10.3 & 8.0 & $6.1 \times 10^{5}$ & 1.0 & 300 \\
*\#7 & 23.3 & 10.8 & $6.7 \times 10^{5}$ & 1.1 & 450 \\
average & $9(2)$ & $8(2)$ & $3(4) \times 10^{6}$ & $0.7(3)$ & \\
\hline
\end{tabular}

$\mathrm{FET}^{29}$. To our knowledge, even the $\langle\mu\rangle$ of $14(4) \mathrm{cm}^{2} \mathrm{~V}^{-1} \mathrm{~s}^{-1}$ for picene- $\left(\mathrm{C}_{14} \mathrm{H}_{29}\right)_{2}$ thin-film FET with PZT gate dielectric is now the third-highest $\mathrm{t}^{29,30}$. The $<\left|V_{\mathrm{th}}\right|>$ does not exceed $11 \mathrm{~V}$ for high- $k$ gate dielectrics. The FET performance achieved using picene- $\left(\mathrm{C}_{14} \mathrm{H}_{29}\right)_{2}$ thin film and high- $k$ gate dielectrics in this study is excellent and satisfactory, but study on the reason why the picene- $\left(\mathrm{C}_{14} \mathrm{H}_{29}\right)_{2}$ thin film provides such FET characteristics should be made, in particular crystal structure analysis is indispensable. Through the work, we must improve the performance rapidly.

The $\mu$ value of our solution-processed FET was lower than that for the previous report ${ }^{32}$. Although the details of the device structure and the formation of the thin film are not clear for the high-performance solution-deposited FET with reported picene- $\left(\mathrm{C}_{14} \mathrm{H}_{29}\right)_{2}$ in ref. 32, the formation of a homogeneous thin film may be a key to higher $\mu$ values, because the obtained thin film by deposition from solution is powder-like, i.e., the growth of an $a b$-plane parallel to the $\mathrm{SiO}_{2}$ surface is not still achieved.

In conclusion, the FET with a PZT gate dielectric achieved a $\langle\mu\rangle$ as high as $14(4) \mathrm{cm}^{2} \mathrm{~V}^{-1} \mathrm{~s}^{-1}$, and the $\left\langle V_{\text {th }}\right\rangle$ was $-7(1) \mathrm{V}$. This $\langle\mu\rangle$ is now the third-highest so far reported for an organic FET, and the highest in FETs based on thin films of pure hydrocarbon molecules. Furthermore, we observed the high $\mu$ values greater than $3 \mathrm{~cm}^{2}$ $\mathrm{V}^{-1} \mathrm{~s}^{-1}$ in all picene- $\left(\mathrm{C}_{14} \mathrm{H}_{29}\right)_{2}$ FETs (see Tables 1-5), especially the maximum $\mu$ reaches $\sim 21 \mathrm{~cm}^{2} \mathrm{~V}^{-1} \mathrm{~s}^{-1}$ with PZT dielectric. Lowvoltage operation $\left(<\left|V_{\mathrm{th}}\right|>\leq \sim 11 \mathrm{~V}\right)$ was achieved with high- $k$ gate dielectrics, implying excellent FET performance of picene$\left(\mathrm{C}_{14} \mathrm{H}_{29}\right)_{2}$ thin film FETs with high $k$-gate dielectrics and an importance of combination of picene- $\left(\mathrm{C}_{14} \mathrm{H}_{29}\right)_{2}$ and high- $k$ gate dielectrics.

This molecule contains long alkyl chains, which may produce a strong interaction between molecules. This seems to lead to the aggregation of granules in thin films prepared from solution, i.e., precipitation is easily produced. Nevertheless, the solution-deposited thin-film FET using this precipitate easily provided p-channel FET characteristics with a $\mu$ as high as $3.4 \times 10^{-2} \mathrm{~cm}^{2} \mathrm{~V}^{-1} \mathrm{~s}^{-1}$. These results show the promise of using an alkyl-substituted picene in the search for a practical high-performance transistor. The observation of the high $\langle\mu\rangle\left(=14(4) \mathrm{cm}^{2} \mathrm{~V}^{-1} \mathrm{~s}^{-1}\right)$ in the FET must open an avenue for ubiquitous electronics based on picene derivatives.

\section{Methods}

Picene- $\left(\mathrm{C}_{14} \mathrm{H}_{29}\right)$ was synthesized using the following reaction steps (see Figure 4). (1) 6-Bromo-1-(bromomethyl)naphthalene 1 was converted to the phosphonium salt 2 by substitution with triphenylphosphine. (2) It was then converted to naphthaldehyde 3 by the Sommelet reaction ${ }^{33}$. (3) A Wittig reaction between compounds 2 and 3 produced dinaphthylethene 4 . $(E)$ - and $(Z)$-isomers of compound 4 were obtained in $52 \%$ and $46 \%$ yields, respectively. It is known that $(E)$-diarylethenes can be used for stilbene-like photocyclization, because $E$-to- $Z$ isomerization occurs under the photoreaction conditions ${ }^{34-36}$. (4) Both $(E)$ - and $(Z)-4$ were used as the precursor to dibromopicene 5 ; a special flow reactor ${ }^{37}$ was used for this reaction. Photocyclization of $(E)$ - and (Z)-4 effectively proceeded to afford dibromopicene 5 in $89 \%$ and $91 \%$ yields, respectively. (5) The tetradecyl chains were introduced by the Kumada-Tamao crosscoupling reaction ${ }^{38}$ in the presence of a Pd catalyst in $75 \%$ yield. The synthesis and experimental details relevant to picene- $\left(\mathrm{C}_{14} \mathrm{H}_{29}\right)_{2}$ in ref. 32 differ from those in this study. The merits of our synthesis are fully described in Supplementary information. 
a

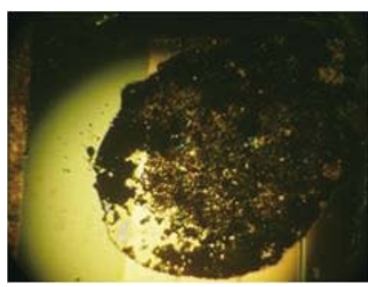

C

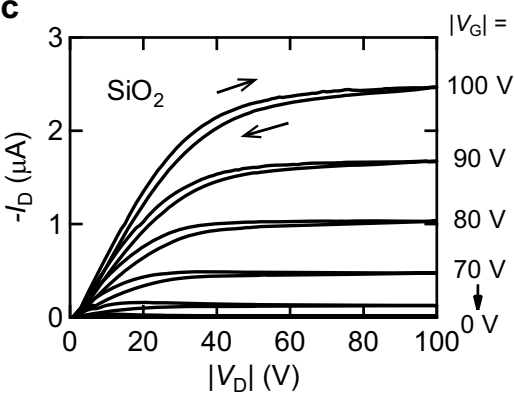

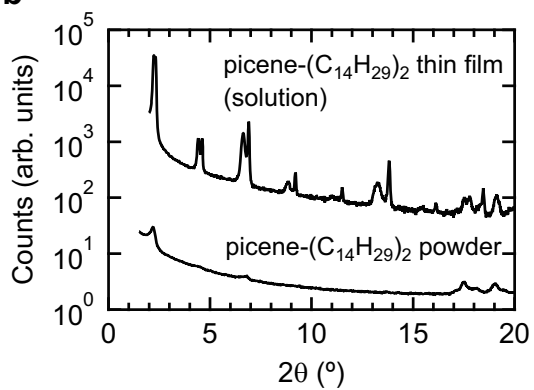

d

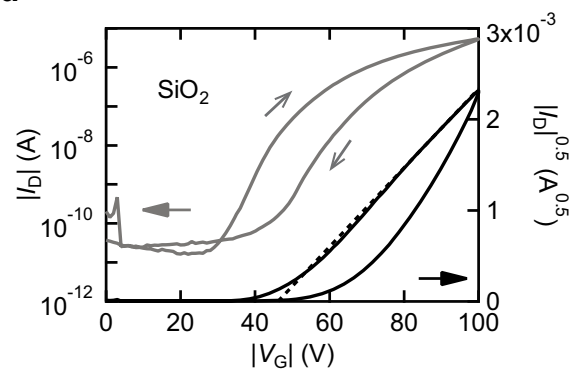

Figure 3 (a) Photograph and (b) XRD patterns of picene- $\left(\mathrm{C}_{14} \mathrm{H}_{29}\right)_{2}$ thin films formed by solution-deposition. In (b) XRD pattern of powder is also shown. (c) Output and (d) transfer curves of FET with picene- $\left(\mathrm{C}_{14} \mathrm{H}_{29}\right)_{2}$ thin films formed by solution-deposition. In $(\mathrm{d}), V_{\mathrm{D}}=-100 \mathrm{~V}$. An SiO ${ }_{2}$ gate dielectric was used. $L$ and $W$ were 100 and $1580 \mu \mathrm{m}$.

Picene- $\left(\mathrm{C}_{14} \mathrm{H}_{29}\right)$ was characterized by NMR spectroscopy (Figure $\mathrm{S} 5$ in Supplementary information) and elemental analysis. In the ${ }^{1} \mathrm{H}$ NMR spectrum, three downfield-shifted signals assignable to the protons located in the bay region of the picene framework were observed: $8.89 \mathrm{ppm}(\mathrm{s}, \mathrm{H}(13,14)), 8.74 \mathrm{ppm}(\mathrm{d}, J=9.1 \mathrm{~Hz}$, $\mathrm{H}(1,11))$ and $8.73 \mathrm{ppm}(\mathrm{d}, J=8.5 \mathrm{~Hz}, \mathrm{H}(6,7))$. The signals of protons at the edges of the picene core appeared in the higher field: $7.76 \mathrm{ppm}(\mathrm{bs}, \mathrm{H}(4,9)), 7.56 \mathrm{ppm}(\mathrm{dd}, J=$ $8.5,1.8 \mathrm{~Hz}, \mathrm{H}(2,12))$. These observations are consistent with the ${ }^{1} \mathrm{H}$ NMR spectral features of previously reported extended phenacene ${ }^{34-36}$, and provide evidence for the presence of pure picene- $\left(\mathrm{C}_{14} \mathrm{H}_{29}\right)_{2}$.

The FET devices using a thin film of picene- $\left(\mathrm{C}_{14} \mathrm{H}_{29}\right)_{2}$ were fabricated on various gate dielectrics such as $\mathrm{SiO}_{2}, \mathrm{Ta}_{2} \mathrm{O}_{5}, \mathrm{ZrO}_{2}, \mathrm{HfO}_{2}$ and $\mathrm{PZT}$. The $\mathrm{SiO}_{2}$ layer was made by thermal oxidation of $\mathrm{Si}$, and we used a commercially available $\mathrm{SiO}_{2} / \mathrm{Si}$ substrate. The other gate dielectrics were synthesized by magnetron RF sputtering for $\operatorname{Pt}(50 \mathrm{~nm}) / \mathrm{Si}$ substrate. The layers of $\mathrm{SiO}_{2}, \mathrm{Ta}_{2} \mathrm{O}_{5}, \mathrm{ZrO}_{2}, \mathrm{HfO}_{2}$ and PZT were 400, 50, 53, 50 and $150 \mathrm{~nm}$ thick, respectively. The surface of gate dielectrics other than $\mathrm{SiO}_{2}$ was coated with $50 \mathrm{~nm}$ thick parylene, while the surface of $\mathrm{SiO}_{2}$ was coated with hexamethyldisilazane (HMDS); the coating methods for parylene and HMDS are described in ref. 39 and Supplementary information, respectively. The capacitance per area, $C_{\mathrm{o}}$, of $\mathrm{SiO}_{2}, \mathrm{Ta}_{2} \mathrm{O}_{5}, \mathrm{ZrO}_{2}, \mathrm{HfO}_{2}$ and PZT were experimentally determined to be $8.3,54,35$, 35 and $36 \mathrm{nF} \mathrm{cm}^{-2}$, respectively, by LCR meter; all $C_{\mathrm{o}}$ was estimated by extrapolation of the capacitance measured at $20 \mathrm{~Hz}-1 \mathrm{kHz}$ to $0 \mathrm{~Hz}$, i.e., the $C_{\mathrm{o}}$ at $0 \mathrm{~Hz}$. The plots of $C_{0}$ - frequency $(f)$ for all gate dielectrics are shown in Figure S8 in Supplementary information. Therefore, the $C_{\mathrm{o}}$ is not underestimated, leading to the exact $\mu$ value.

The thin film of picene- $\left(\mathrm{C}_{14} \mathrm{H}_{29}\right)_{2}$ was formed by either thermal deposition at $10^{-7}$ Torr or deposition from a $\mathrm{CHCl}_{3}$ solution. The thin film prepared by thermal deposition was $60 \mathrm{~nm}$ thick, while the thickness of the solution-deposited film was more than $1 \mu \mathrm{m}$. Details of the solution-deposition process are described in Supplementary information. The source and drain electrodes were formed with gold (Au) by thermal deposition at $10^{-7}$ Torr. The thickness of Au electrodes was $50 \mathrm{~nm}$. $3 \mathrm{~nm}$ thick $\mathrm{F}_{4}$ TCNQ was inserted into the space between electrodes and thin film. The channel length, $L$, and width, $W$, of the FET device are specified in figure captions and tables. The device structure (top-contact type) is shown in Figure 1(b). The FET characteristics were recorded in two-terminal measurement mode using a semiconductor parametric analyzer (Agilent B1500A) in an Ar-filled glove box; in measurement of FET characteristics, the source voltage, $V_{\mathrm{S}}$, is grounded (sourcegrounded), or $V_{\mathrm{S}}=0 \mathrm{~V}$. All FET parameters are evaluated from the square root of absolute forward transfer curve $\left(\left|I_{\mathrm{D}}\right|^{1 / 2}-V_{\mathrm{G}}\right)$ because of a saturation regime; the $\left|I_{\mathrm{D}}\right|^{1 / 2}$ - $V_{\mathrm{G}}$ curves are shown for all transfer curves in this paper.

To check the statistical reproducibility of FET characteristics, the FET characteristics of picene- $\left(\mathrm{C}_{14} \mathrm{H}_{29}\right)_{2}$ thin film FETs with various dielectrics are summarized in Tables $1-5$. The average values and the standard deviations of FET parameters are shown in the bottom row. The transfer and output curves of sample \#1 in each table (see Tables 1-5) are shown in this paper, and the FET characteristics are described in the main text. The sample indicated by an asterisk in Table 5 is not used for average, because it shows much higher mobility than those for the other samples in Table 5. The channel width is $500 \mu \mathrm{m}$ for the devices with $\mathrm{SiO}_{2}, \mathrm{HfO}_{2}, \mathrm{Ta}_{2} \mathrm{O}_{5}$, and $\mathrm{ZrO}_{2}$ dielectrics, and $600 \mu \mathrm{m}$ for the devices with a PZT dielectric.

The XRD and AFM were measured using Smart Lab-Pro (RIGAKU) and an SPA 400-DFM (SII Nano Technologies), respectively. The X-ray wavelength was $1.5418 \AA$ ( $\mathrm{Cu} \mathrm{K} \alpha$ source).

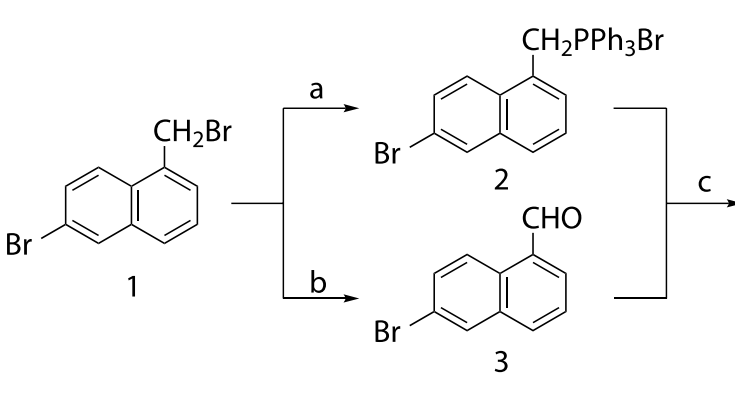<smiles>Brc1ccc2c(C=Cc3cccc4cc(Br)ccc34)cccc2c1</smiles>

4<smiles>Brc1ccc2c(ccc3c2ccc2c4ccc(Br)cc4ccc23)c1</smiles>

5

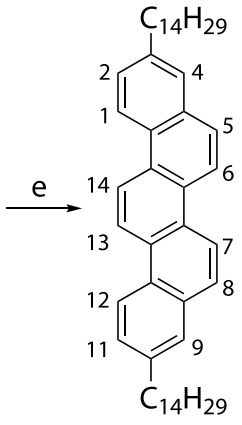

picene- $\left(\mathrm{C}_{14} \mathrm{H}_{29}\right)_{2}$

Figure 4 Synthetic route to picene- $\left(\mathrm{C}_{14} \mathrm{H}_{29}\right)_{2}$. (a) $\mathrm{PPh}_{3}$, toluene, reflux $18 \mathrm{~h}, 95 \%$; (b) hexamethylenetetramine, $\mathrm{CHCl}_{3}$, reflux, $1 \mathrm{~h}$, then heat in AcOH$\mathrm{H}_{2} \mathrm{O}$ for 1.5 h, 72\%; (c) KOH, $\mathrm{CH}_{2} \mathrm{Cl}_{2}-\mathrm{H}_{2} \mathrm{O}$, r.t., 17 h, (E)-4 52\%, (Z)-4 46\%; (d) hv (flow reactor) ${ }^{37}, \mathrm{I}_{2}, \mathrm{O}_{2}$, toluene, irradiation time 15 min, $89 \%$. (e) $\mathrm{C}_{14} \mathrm{H}_{29} \mathrm{MgBr}, \mathrm{PdCl}_{2}$ (dppf) $-\mathrm{CH}_{2} \mathrm{Cl}_{2}, 75 \%$. 
1. Braga, D. \& Horowitz, G. High-performance organic field-effect transistors. $A d v$. Mater. 21, 1473-1486 (2009).

2. Sirringhaus, H. Device physics of Solution-processed organic field-effect transistors. Adv. Mater. 17, 2411-2425 (2005).

3. Kuwahara, E. et al. Fabrication of ambipolar field-effect transistor device with heterostructure of C-60 and pentacene. Appl. Phys. Lett. 85, 4565-4567 (2004).

4. Jang, Y. et al. Influence of the dielectric constant of a polyvinyl phenol insulator on the field-effect mobility of a pentacene-based thin-film transistor. Appl. Phys. Lett. 87, 152105 (2005).

5. Kang, G. W., Park, K.-M., Song, J.-H., Lee, C. H. \& Hwang, D. H. The electrical characteristics of pentacene-based organic field-effect transistors with polymer gate insulators. Current. Appl. Phys. 5, 297-301 (2005).

6. Tamura, R., Lim, E., Manaka, T. \& Iwamoto, M. Analysis of pentacene field effect transistor as a Maxwell-Wagner effect element. J. Appl. Phys. 100, 114515 (2006).

7. Lim, E., Manaka, T. \& Iwamoto, M. Analysis of carrier injection into a pentacene field effect transistor by optical second harmonic generation measurements. J. Appl. Phys. 101, 024515 (2007).

8. Ogawa, S., Naijo, T., Kimura, Y., Ishii, H. \& Niwano, M. Photoinduced doping effect of pentacene field effect transistor in oxygen atmosphere studied by displacement current measurement. Appl. Phys. Lett. 86, 252104 (2005).

9. Lim, E., Manaka, T., Tamura, R. \& Iwamoto, M. Analysis of hysteresis behaviour of pentacene field effect transistor characteristics with capacitance-voltage and optical second harmonic generation measurements. J. Appl. Phys. 101, 094505 (2007).

10. Kim, D. H., Lee, H. S., Yang, H., Yang, L. \& Cho, K. Tunable crystal nanostructures of pentacene thin films on gate dielectrics possessing surface-order control. $A d v$. Funct. Mater. 18, 1363-1370 (2008).

11. Pal, B. N., Trottmam, P., Sun, J. \& Katz, H. E. Solution-deposited zinc oxide and zinc oxide/pentacene bilayer transistors: High mobility n-channel, ambipolar and nonvolatile devices. Adv. Funct. Mater. 18, 1832-1839 (2008).

12. Yan, H., Kagata, T. \& Okuzaki, H. Ambipolar pentacene/C-60-based field-effect transistors with high hole and electron mobilities in ambient atmosphere. Appl. Phys. Lett. 94, 023305 (2009).

13. Okamoto, H. et al. Air-assisted high-performance field-effect transistor with thin films of picene. J. Am. Chem. Soc. 130, 10470-10471 (2008).

14. Kawasaki, N., Kubozono, Y., Okamoto, H., Fujiwara, A. \& Yamaji, M. Trap states and transport characteristics in picene thin film field-effect transistor. Appl. Phys. Lett. 94, 043310 (2009).

15. Lee, X. et al. Quantitative analysis of O-2 gas sensing characteristics of picene thin film field-effect transistors. Org. Electron. 11, 1394-1398 (2010).

16. Kaji, Y. et al. Low voltage operation in picene thin film field-effect transistor and its physical characteristics. Appl. Phys. Lett. 95, 183302 (2009).

17. Sugawara, Y. et al. $\mathrm{O}_{2}$-exposure and light-irradiation properties of picene thin film field-effect transistor: A new way toward $\mathrm{O}_{2}$ gas sensor. Sensors and Actuators $B$, 171/172, 544-549 (2012)

18. Komura, N. et al. Characteristics of [6]phenacene thin film field-effect transistor. Appl. Phys. Lett. 101, 083301 (2012).

19. Eguchi, R. et al. Fabrication of high performance/highly functional field-effect transistor devices based on [6] phenacene thin films. Phys. Chem. Chem. Phys. 15, 20611-20617 (2013).

20. Sugawara, Y. et al. Characteristics of field-effect transistors using the onedimensional extended hydrocarbon [7]phenacene. Appl. Phys. Lett. 98, 013303 (2011).

21. Kang, M. J. et al. Alkylated dinaphtho[2,3-b:2 ', $\left.3^{\prime}-\mathrm{f}\right]$ thieno[3,2-b] thiophenes (C$\mathrm{n}$-DNTTs): Organic semiconductors for high-performance thin-film transistors. Adv. Mater. 23, 1222-1225 (2011).

22. Kawasugi, Y. et al. Strain-induced superconductor/insulator transition and field effect in a thin single crystal of molecular conductor. Appl. Phys. Lett. 92, 243508 (2008).

23. Podzorov, V., Pudalov, V. M. \& Gershenson, M. E. Field-effect transistors on rubrene single crystals with parylene gate insulator. Appl. Phys. Lett. 82, 1739-1741 (2003).

24. Podzorov, V. et al. Intrinsic charge transport on the surface of organic semiconductors. Phys. Rev. Lett. 93, 086602 (2004).

25. Sundar, V. C. et al. Elastomeric transistor stamps: Reversible probing of charge transport in organic crystals. Science, 303, 1644-1646 (2004).

26. Kawai, N. et al. Characteristics of single crystal field-effect transistors with a new type of aromatic hydrocarbon, picene. J. Phys. Chem. C 116, 7983-7988 (2012).

27. He, X. et al. Fabrication of single crystal field-effect transistors with phenacenetype molecules and their excellent transistor characteristics. Org. Electron. 14, 1673-1682 (2013).
28. Kubozono, Y. et al. Metal-intercalated aromatic hydrocarbons: a new class of carbon-based superconductors. Phys. Chem. Chem. Phys. 13, 16476-16493 (2011).

29. Amin, A. Y., Khassanov, A., Reuter, K., Meyer-Friedrichsen, T. \& Halik, M. Lowvoltage organic field effect transistors with a 2-tridecyl[1]benzothieno[3,2b][1]benzothiophene semiconductor layer. J. Am. Chem. Soc. 134, 16548-16550 (2012).

30. Kurihara, N. et al. High-mobility organic thin-film transistors over $10 \mathrm{~cm}(2) \mathrm{V}-1$ $\mathrm{s}(-1)$ fabricated using bis(benzothieno) naphthalene polycrystalline films. Jpn. J. Appl. Phys. 52, 05DC11 (2013).

31. Nishihara, Y. et al. Phenanthro[1,2-b: 8,7-b '] dithiophene: a new picene-type molecule for transistor applications. RSC Adv. 3, 19341-19347 (2013).

32. Nakano, H., Saito, T. \& Nakamura, H. PCT/Japan Patent Kokai WO2010-016511 (2010).

33. Angyal, S. J. The Sommelet Reaction. Org. React. 8, 197 (1954)

34. Mallory, F. B., Butler, K. E., Evans, A. C. \& Mallory, C. W. Phenacenes: A family of graphite ribbons .1. Syntheses of some [7]phenacenes by stilbene-like photocyclizations. Tetrahedron Lett. 40, 7173-7176 (1996).

35. Mallory, F. B. et al. Phenacenes: A family of graphite ribbons .2. Syntheses of some [7]phenacenes and an [11]phenacene by stilbene-like photocyclizations. J. Am. Chem. Soc. 119, 2119-2124 (1997).

36. Mallory, F. B. et al. Phenacenes: a family of graphite ribbons. Part 3: Iterative strategies for the synthesis of large phenacenes. Tetrahedron 57, 3715-3724 (2001).

37. Hook, B. D. A. et al. A practical flow reactor for continuous organic photochemistry. J. Org. Chem. 70, 7558-7564 (2005).

38. Kumada, M. Nickel and palladium complex catalyzed cross-coupling reactions of organometallic reagents with organic halides. Pure Appl. Chem. 52, 669-679 (1980).

39. Kawasaki, N. et al. Flexible picene thin film field-effect transistors with parylene gate dielectric and their physical properties. Appl. Phys. Lett. 96, 113305 (2010).

\section{Acknowledgments}

The authors greatly appreciate Ms. Saki Nishiyama for her kind assistance for FET measurements. This study is partly supported by Grants-in-aid (23684028, 22244045, $24654105,24550054)$ from MEXT, by the Program to Disseminate the Tenure Tracking System of the Japan Science and Technology Agency (JST), by the LEMSUPER Project (JSTEU Superconductor Project) and the ACT-C Project of the JST, and by the Program for Promoting the Enhancement of Research Universities.

\section{Author contributions}

H.O., Y.K. and R.E. designed this research project and supervised experiments. H.O. and S.G. performed synthesis and characterization of picene- $\left(\mathrm{C}_{14} \mathrm{H}_{29}\right)_{2}$ sample. S.H., R.E. and H.G. carried out FET works and characterization of thin films. Y.S. and M.I. performed works of XRD and AFM. H.O. and R.E. wrote the parts of synthesis and FET work of this paper, respectively, and YK combined them and modified to complete the paper. S.H., H.G. and Y.K. carried out the additional experiments and analyses on the durability and reproducibility of FET performance. R.E. managed (edited) all parts of this paper under the discussion with Y.K.

\section{Additional information}

Supplementary information accompanies this paper at http://www.nature.com/ scientificreports

Competing financial interests: The authors declare no competing financial interests. How to cite this article: Okamoto, H. et al. Transistor application of alkyl-substituted picene. Sci. Rep. 4, 5048; DOI:10.1038/srep05048 (2014).

This work is licensed under a Creative Commons Attribution-NonCommercialNoDerivs 3.0 Unported License. The images in this article are included in the article's Creative Commons license, unless indicated otherwise in the image credit; if the image is not included under the Creative Commons license, users will need to obtain permission from the license holder in order to reproduce the image. To view a copy of this license, visit http://creativecommons.org/licenses/by-nc-nd/3.0/ 